\title{
Formation of poikilitic chromite in the basal dunite series of the 2.44 Ga Näränkävaara layered intrusion
}

\author{
V. Järvinen ${ }^{1 *}$, T. Halkoaho ${ }^{2}$ \\ ${ }^{1}$ University of Helsinki1 \\ ${ }^{2}$ Geological Survey of Finland \\ *Corresponding author e-mail: ville.jarvinen@helsinki.fi
}

\begin{abstract}
Summary Poikilitic chromite has been described only from komatiitic cumulates with $>\mathrm{Fo}_{91-92}$. Its formation is thought to be related to high temperatures inhibiting chromite nucleation. Here, we describe poikilitic chromites found in the olivine adcumulate $\left(\mathrm{Fo}_{<91}\right)$ basal dunite series of the Näränkävaara intrusion, and suggest a formation mechanism for poikilitic chromite in intrusive settings whereby low oxygen fugacity in the parental magma inhibits chromite nucleation. Results of this and other recent studies from the Näränkävaara intrusion are summarized, and implications for massive sulfide exploration in Fennoscandian 2.44 Ga intrusions are presented.
\end{abstract}

\section{Introduction and background to current research}

Fine grained interstitial chromites are commonly found in ultramafic cumulates in mafic intrusions (e.g. Great Dyke; Wilson 1982), but true coarse grained poikilitic chromites have not been described from these settings (cf. Godel et al. 2013; Latypov et al. 2020). Poikilitic chromites enclosing olivine are commonly described from komatiitic olivine adcumulates with Fo92-95. It is hypothesized that high temperatures of the komatiitic parental magmas (proxied by high Fo) inhibit chromite nucleation, so that when chromite finally nucleates it grows rapidly into sparse but coarse poikilitic grains (Barnes 1998). Latypov et al. (2020) investigated the crystallization of new liquidus phases (including silicates) in mafic intrusions, and similarly concluded that a finite amount of supercooling of a melt below the liquidus (i.e, supersaturation of a phase) is required to overcome the kinetic energy related to nucleating a new phase; when a new phase nucleates, the first grains grow rapidly from the now oversaturated melt into large poikilitic crystals.

Here, we describe coarse grained poikilitic chromites found in the 1.5-2 km thick basal dunite series (BD) of the mafic-ultramafic 2.44 Ga Näränkävaara layered intrusion, Northern Finland. These chromites are hosted in olivine adcumulates containing $<$ Fo91 olivines, formed from parental magmas with, at most, 15-18 wt \% MgO (Järvinen et al. 2020b). High temperatures cannot easily be invoked to explain formation of these poikilitic chromites. We present evidence for low $f_{\mathrm{O}_{2}}$ in the parental magma of these chromites, and suggest a hypothesis whereby low $f_{\mathrm{O}_{2}}$ has inhibited chromite nucleation.

\section{Materials and Results}

The $2.44 \mathrm{Ga}$ Näränkävaara intrusion is $25 \mathrm{~km} \times 5 \mathrm{~km}$, and about $3 \mathrm{~km}$ thick in stratigraphy (Järvinen et al. 2020a,b). It includes two major cumulate series: 1) the 1.5-2 km thick basal dunite series composed of olivine adcumulates, with an olivine orthocumulate southern margin ( $2441 \pm 1 \mathrm{Ma}$; Järvinen et al. submitted a) in contact with the Archean basement gneiss; and the 2) $1.3 \mathrm{~km}$ thick layered series $(2436 \pm 5 \mathrm{Ma})$ composed of peridotites, pyroxenites, gabbronorites, and diorites.

Study materials are electron probe microanalysis (EPMA) results from chromites from a sampling profile across the SE block the BD ( $A$ in Fig. 1) (Järvinen et al. 2020b). According 
to lithology, the profile is divided into three zones (BD-1 to BD-3 in Fig. 2). Zone BD-1 contains marginal olivine orthocumulates which grade into adcumulates, ending in a thin unit of monomineralic orthopyroxenite (blue symbols in Fig. 2). Zone BD-2 is composed of very low porosity olivine adcumulates with minor mesocumulates (generally $>97$ vol\% olivine). Zone BD-3 is composed of olivine-orthopyroxene heteradcumulates and minor orthopyroxenites.

Non-poikilitic chromites are fine grained with habits ranging from euhedral to anhedral intercumulus. Poikilitic chromites are coarse grained $(<2 \mathrm{~mm})$ with lobate or poikilitic habits (Fig. 2). Chromite mode is always $<1-2$ vol\%; however, non-poikilitic chromites are found in significantly higher overall abundances compared to poikilitic chromites, as illustrated by whole-rock $\mathrm{Cr}$ in Fig. 2.

Chromite $\mathrm{Fe}^{3+} \#$ 's $\left(\mathrm{Fe}^{3+} /\left[\mathrm{Cr}^{3+}+\mathrm{Al}^{3+}+\mathrm{Fe}^{3+}\right]\right)$ are plotted against height in Fig. 2. The lowest $\mathrm{Fe}^{3+} \#$ are found in samples with poikilitic chromite (i.e., in samples with lowest modal chromite and lowest whole-rock Cr), in zone BD-2 and base of zone BD-3.

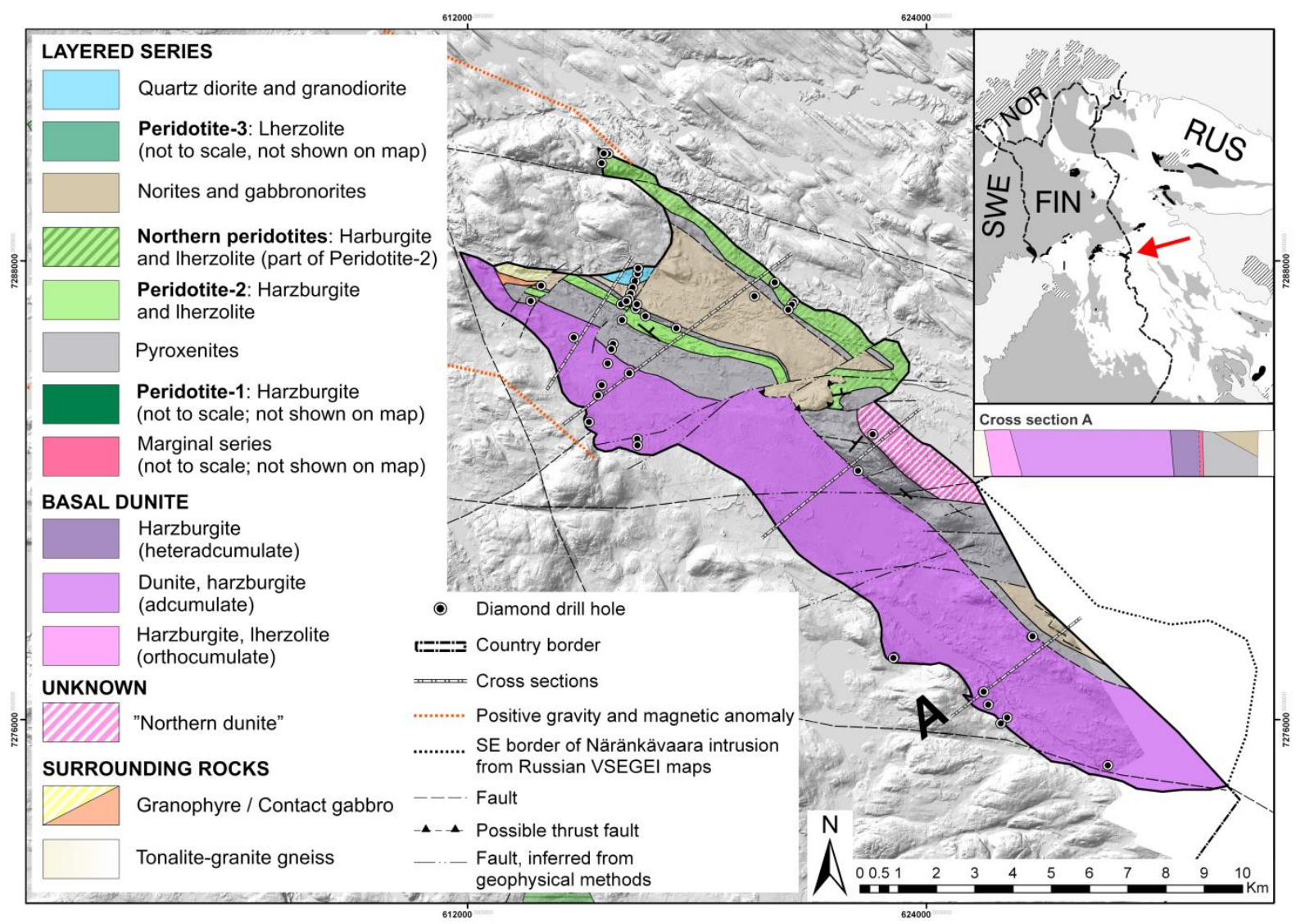

Figure 1. The 2.44 Ga mafic-ultramafic Näränkävaara intrusion. Study materials from cross-section $A$ (see lower inset).

\section{Discussion}

Chromite $\mathrm{Fe}^{3+} \#$ is sensitive to changes in the oxygen fugacity of its parental magma (Murck \& Campbell 1986). Range of $\mathrm{Fe}^{3+} \#$ in the BD is $0.02-0.10 \mathrm{~mol} \%$, corresponding to approximately -6 to $-9 \log f_{\mathrm{O}_{2}}$ at the liquidus $\mathrm{T}\left(1350-1400^{\circ} \mathrm{C}\right)$ of the BD parental magma (Murck \& Campbell 1986; Järvinen et al. 2020b). The lowest $\mathrm{Fe}^{3+} \#$ values indicate minimum oxygen buffer of -1 to -2 log unit below QFM. In basaltic-komatiitic liquids, chromite liquidus is elevated by high T (Barnes 1998), but also by low $f_{\mathrm{O}_{2}}$ (Hill \& Roeder 1974). These effects are illustrated in Fig. 3 with the basal dunite samples. Thus, the Näränkävaara poikilitic chromites are interpreted to have crystallized from highly reduced magmas. 
Zone BD-1 represents the initial emplacement of the BD (dated $2441 \pm 1 \mathrm{Ma}$ ). We propose these initial magmas interacted with crustal wall-rocks, assimilating external oxygen. Initial emplacement was followed by pooling, fractionation, and formation of orthopyroxenites (blue in Fig. 2). The following more voluminous magmas producing the thick olivine adcumulates of BD-2 were insulated from wall-rocks by the preceding orthocumulates, and show reduced compositions as described for mantle sourced magmas (Simakov 1998). As oxygen fugacity increased towards the top of zone BD-3, chromite nucleation increased and higher abundance of fine grained cumulus chromite was again formed (Fig. 2). This sequence of poikilitic followed by cumulus crystallization agrees with that predicted in Latypov et al. (2020).

A similar lithological and mineral chemical sequence (from high to low $\mathrm{Fe}^{3+} \#$ ) is also found in the olivine orthocumulates along the north-western border of the Näränkävaara intrusion (Fig. 1). These cumulates are associated with a later magma pulse causing the PER-2 reversal found in the layered series (Järvinen et al. submitted b). The capability of the $2.44 \mathrm{Ga}$ parental magmas to assimilate wall-rocks may have been diminished by formation of such initial olivine orthocumulate layers insulating magma channels from wall-rocks. Combined with the possibility of deep (early) large-scale homogenization of primary plume magmas with crustal contaminants, and the resulting decrease in magma temperatures, the massive sulfide prospectivity of these systems may be decreased (cf. Gole \& Barnes 2020). Identification of easily soluble sulfur-bearing wall-rocks (e.g. anhydrites), and evidence of external sulfur addition (e.g., textural, proportional, mineral chemical, isotopic), would be key factors for massive sulfide exploration.

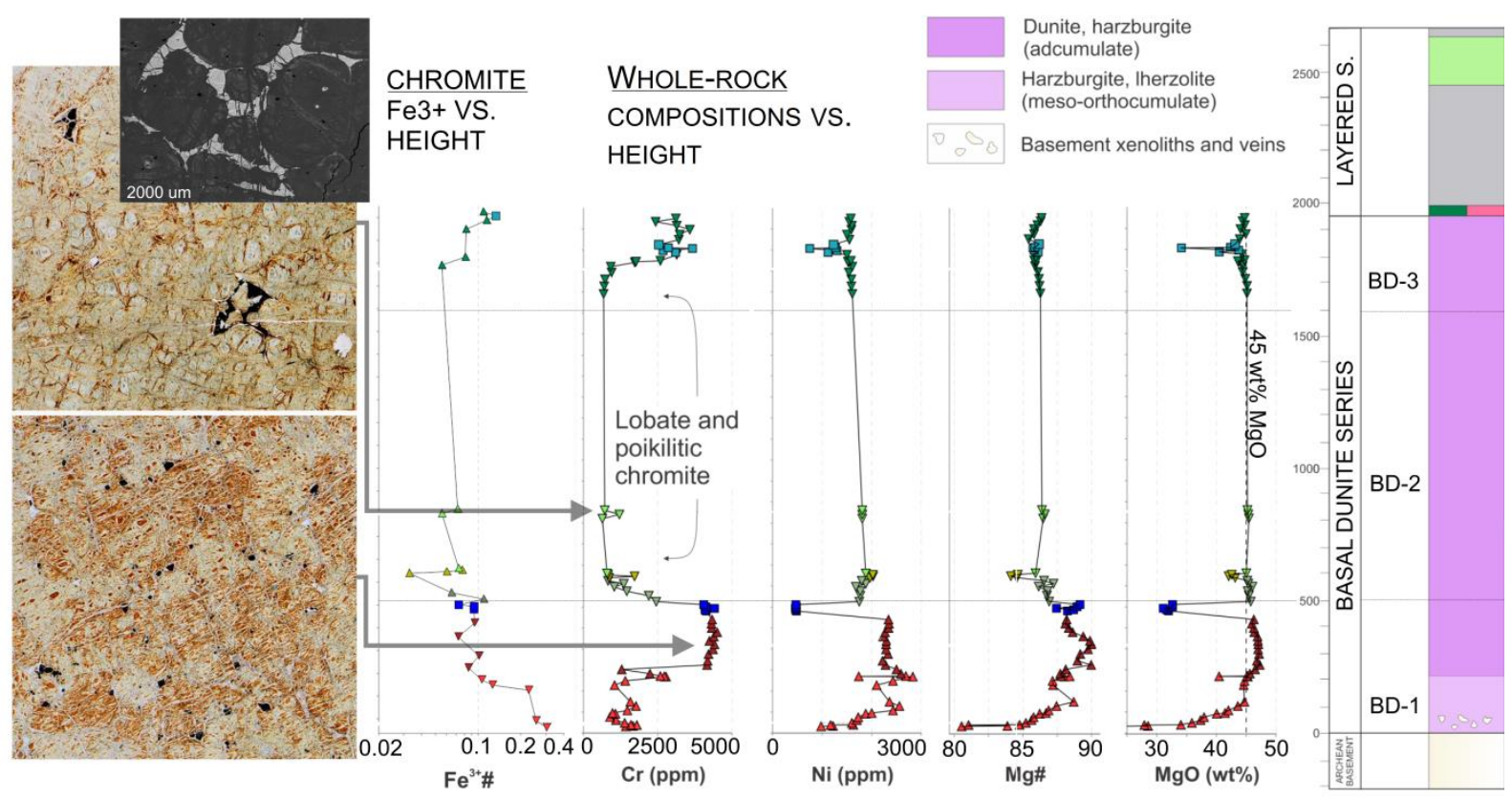

Figure 2. Whole-rock and mineral chemical variations along cross-section $A$ in Fig. 1. Note correlation between low chromite $\mathrm{Fe}^{3+} \#$ and low whole-rock Cr. Left shows thin-section photos of olivine adcumulates with poikilitic (top) and cumulus (bottom) chromites; Upper-left shows back-scattered electron (BSE) image of $2 \mathrm{~mm}$ poikilitic chromite grain in zone BD-2. 


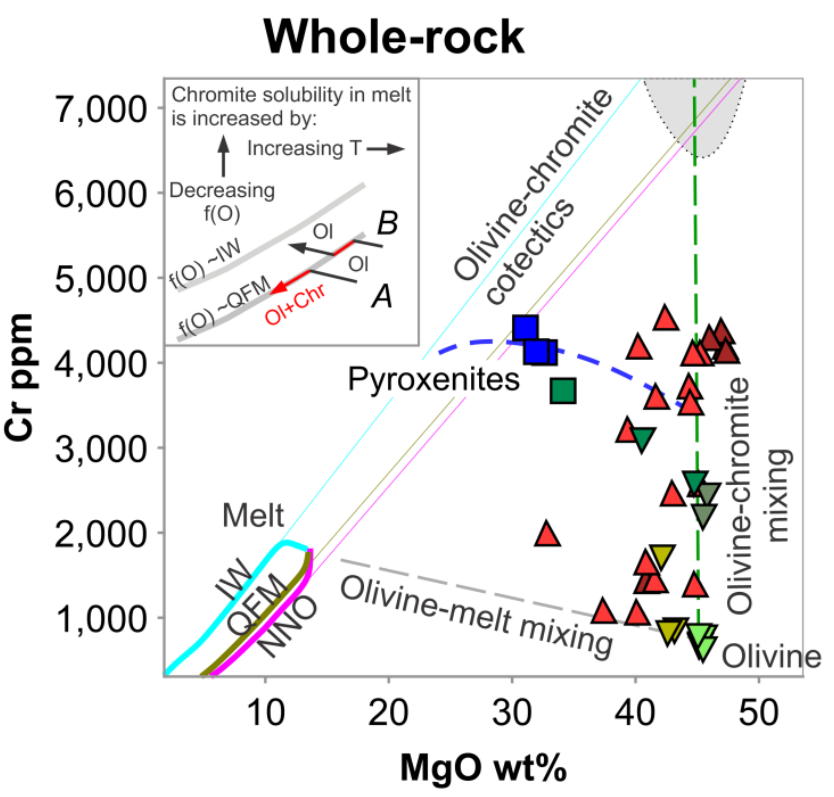

Figure 3. Whole-rock $\mathrm{MgO}$ vs. $\mathrm{Cr}$ in the Näränkävaara basal dunite samples in Fig. 2 . In inset: a cooling and fractionating high-T melt $(A)$ first crystallizes olivine (black), and then olivine+chromite (red) as the melt arrives on the chromite saturation surface (grey); increase in melt $\mathrm{T}$ or $f_{\mathrm{O}_{2}}$ will move phase equilibria away from olivine+chromite back to pure olivine $(B)$. High-Cr samples in the basal dunite have crystallized from a near-QFM magma along the olivinechromite cotectic (however, at sub-cotectic proportions); whereas low-Cr samples have crystallized from a more reduced magma with low $f_{\mathrm{O}_{2}}$ inhibiting chromite nucleation. Exception are some low-Cr marginal olivine orthocumulates which represent olivine-melt mixing (bright reds). Modelled liquid lines of descent for Näränkävaara parental magmas at various oxygen fugacities are labelled (IW, QFM, NNO).

\section{References:}

Barnes SJ (1998) Chromite in Komatiites, 1. Magmatic Controls on Crystallization and Composition. J Petrol 39(10):1689-1720

Godel B, Barnes SJ, Gürer D et al (2013) Chromite in komatiites: 3D morphologies with implications for crystallization mechanisms. Contrib Mineral Petrol 165:173-189. doi:10.1007/s00410-012-0804-y

Gole MJ \& Barnes SJ (2020) The association between Ni-Cu-PGE sulfide and Ni-Co lateritic ores and volcanic facies within the komatiites of the $2.7 \mathrm{Ga}$ East Yilgarn Craton large igneous province, Western Australia. Ore Geol Rev 116:1-21. doi: 10.1016/j.oregeorev.2019.103231

Hill R, Roeder P (1974) The Crystallization Of Spinel From Basaltic Liquid As A Function Of Oxygen Fugacity. J Geol 82:709-729

Järvinen V, Halkoaho T, Konnunaho J et al (2020a) Parental magma, magmatic stratigraphy, and reef-type PGE enrichment of the 2.44-Ga mafic-ultramafic Näränkävaara layered intrusion, Northern Finland. Miner Depos 55:1535-1560

Järvinen V, Halkoaho T, Konnunaho J et al (2020b) The basal dunite of the Precambrian mafic-ultramafic Näränkävaara intrusion: Petrogenetic considerations and implications to exploration. Miner Petrol 115:3761

Järvinen V, Halkoaho T, Konnunaho J et al (submitted a) Petrogenesis of the Paleoproterozoic Näränkävaara layered intrusion, northern Finland, Part I: the northern peridotites and their relationships with the layered series and recharge events. Submitted to Precambrian Research in Dec/2021; manuscript available on request.

Järvinen V, Halkoaho T, Konnunaho J et al (submitted b) Petrogenesis of the Paleoproterozoic Näränkävaara layered intrusion, northern Finland, Part II: U-Pb age and $\mathrm{Sm}-\mathrm{Nd}$ isotope systematics. Submitted to Precambrian Research in Dec/2021; manuscript available on request.

Latypov RM, Yu S, Namur O et al (2020) - Dynamics of evolving magma chambers: textural and chemical evolution of cumulates at the arrival of new liquidus phases. Earth Sci Rev 210, 32 pp. doi:10.1016/j.earscirev.2020.103388

Murck BW, Campbell IH (1986) The effects of temperature, oxygen fugacity and melt composition on the behaviour of chromium in basic and ultrabasic melts. Geochim Cosmochim Acta 50:1871-1887

Simakov SK (1998) Redox state of Earth's upper mantle peridotites under the ancient cratons and its connection with diamond genesis. Geochim Cosmochim Acta 62:1811-1820

Wilson AH (1982) The Geology of the Great Dyke, Zimbabwe: The Ultramafic Rocks. J Petrol 23(2):240-292 